Pacific Journal of Mathematic 


\section{GAP SERIES AND AN EXAMPLE TO MALLIAVIN'S THEOREM}

\section{ROBERT KAUFMAN}

\section{Malliavin's celebrated theorem of spectral nonsynthesis} is based on a real function $f$ of class $A$

$$
\begin{gathered}
f(t)=\sum_{n=1}^{\infty} a_{n} \cos n t+\sum_{n=1}^{\infty} b_{n} \sin n t, \\
\sum\left|a_{n}\right|+\sum\left|b_{n}\right|<\infty,
\end{gathered}
$$

for which $\int_{-\infty}^{\infty}|u|\left\|e^{i u f}\right\|_{\infty} d u<\infty$.

Here and in general $\|g\|_{\infty} \equiv \sup _{n}|\hat{g}(n)|$. This note presents a method for constructing a function $f$, based on a gap property and a method of estimation of Kahane.

Let $0<n_{1}<n_{2}<\cdots<n_{k}<\cdots$ be a sequence of integers with the property:

Whenever $\varepsilon_{k}=0, \pm 1$, and $\varepsilon_{1} n_{1}+\cdots+\varepsilon_{N} n_{N}=0$, then $\varepsilon_{1}=\varepsilon_{2}=$ $\cdots=\varepsilon_{N}=0$.

Let $\omega_{1}, \omega_{2}, \cdots, \omega_{k}, \cdots$ be independent random variables defined upon a probability space $\Omega$, distributed uniformly upon [0,2 $\pi$. For a number $0<b<1$ set

$$
f(t)=\sum_{k=1}^{\infty} b^{k} \cos \left(n_{k} t+\omega_{k}\right) .
$$

Then, for each integer $M \geqq 1$ there is a $b=b(M)<1$ such that

$$
\int_{-\infty}^{\infty}|u|^{M}\left\|e^{i u s}\right\|_{\infty} d u<\infty \text { for almost all } \omega \text { in } \Omega .
$$

REmaRKs. Choosing $n_{k}=2^{k}$, we obtain a function $f$ of class $\operatorname{Lip}(-\log b / \log 2)$, and this shows that $b(M)$ must converge to 1 as $M \rightarrow \infty$. For if the integral in (1) is finite, there is a number $\xi$ such that $(f-\xi)^{M}$ does not admit synthesis, and it must be false that

$$
|f(t)-\xi|^{2 M}=O\left(d\left(t, f^{-1}(\xi)\right)\right),
$$

[3, pp. 116, 122]. But then $f \notin \operatorname{Lip}\left(2^{-1 / M}\right)$. Functions $f$ with the Lipschitz condition were first produced in [1], and an explicit examplethat is, nonprobabilistic-given in [2].

1. Let $0<r<1,0<\varepsilon, 0<\eta<(1-r) \log 5-\log 4$. Define $B_{N}(s, t)$ for $0<s, t<2 \pi(N=1,2,3, \cdots)$ to be the number of integers $k$ defined by 


$$
1 \leqq k \leqq N, \quad\left|\cos n_{k} s-\cos n_{k} t\right| \geqq \varepsilon .
$$

LEMma. If $\varepsilon>0$ is small enough, the Lebesgue measure

$$
m\left\{B_{N}(s, t) \leqq r N\right\}=O\left(e^{-\eta \cdot M}\right), \quad \text { as } \quad N \rightarrow \infty .
$$

Proof. Set

$$
\xi_{k}(s, t)=5-\left(\cos n_{k} s-\cos n_{k} t\right)^{2}
$$

or

$$
\xi_{k}=4-\frac{1}{2} \cos 2 n_{k} s+2 \cos n_{k} s \cos n_{k} t-\frac{1}{2} \cos 2 n_{k} t .
$$

The mean of the product $\xi_{1} \cdots \xi_{V}$ is $4^{N}$. For the product is a sum of terms

$$
c \Pi^{\prime} \cos 2 n_{k} s \Pi^{\prime \prime} \cos n_{k} s \cos n_{k} t \Pi^{\prime \prime \prime} \cos 2 n_{k} t,
$$

where the symbols $\Pi^{\prime}$, etc., refer to products over mutually disjoint subsets of $\{1,2, \cdots, N\}$. If such a sum has mean $\neq 0$, it is trivial, for there are integers $\varepsilon_{k}= \pm 1, \delta_{k}= \pm 1$, defined for every exponent $n_{k}$ present, such that $2 \Sigma^{\prime} \varepsilon_{k} n_{k}+\Sigma^{\prime \prime} \varepsilon_{k} n_{k}=\Sigma^{\prime \prime} \delta_{k} n_{k}+2 \Sigma^{\prime \prime \prime} \hat{o}_{k} n_{k}=0$. But $\Sigma^{\prime} \varepsilon_{k} n_{k}+\frac{1}{2} \Sigma^{\prime \prime}\left(\varepsilon_{k}+\delta_{k}\right) n_{k}+\Sigma^{\prime \prime \prime} \delta_{k} n_{k}=0$, where $\frac{1}{2}\left(\varepsilon_{k}-\delta_{k}\right)=0, \pm 1$. Thus $\Pi^{\prime}$ and $\Pi^{\prime \prime \prime}$ must be trivial, and so finally $\Pi^{\prime \prime}$ is trivial.

Now

$$
\left\{B_{N} \leqq r N\right\} \subseteq\left\{\xi_{1} \cdots \xi_{N} \geqq\left(5-\varepsilon^{2}\right)^{(1-r) N}\right\},
$$

so

$$
m\left\{B_{N} \leqq r N\right\} \leqq 4 \pi^{2}\left[4 /\left(5-\varepsilon^{2}\right)^{1-r}\right]^{N},
$$

and we need only choose $\varepsilon>0$ so that $\eta<(1-r) \log \left(5-\varepsilon^{2}\right)-\log 4$. We now choose $\varepsilon>0, \eta>0,1>r>0$, once and for all.

2. Following [1] we observe that for $g$ in $L^{2}$

$$
\begin{gathered}
g(t)=\sum_{-\infty}^{\infty} c_{n} e^{i n t} \\
(g * g)(t)=(2 \pi)^{-1} \int g(t-s) g(s) d s=\sum_{-\infty}^{\infty} c_{n}^{2} e^{i n t} \\
\|g * g\|_{2}^{2}=(2 \pi)^{-1} \iiint g(t-s) g(s) g(\overline{t-p}) g(\bar{p}) d s d t d p=\sum_{-\infty}^{\infty}\left|c_{n}\right|^{4} \geqq\|g\|_{\infty}^{4} .
\end{gathered}
$$

Set

$$
\begin{aligned}
& P(x, y, z, \omega) \\
& \quad=\cos (x-y+\omega)+\cos (y+\omega)-\cos (x-z+\omega)-\cos (z+\omega) .
\end{aligned}
$$


For fixed $x, y, z, P$ is a trigonometric monomial in $\omega$, say $\tau \sin (\omega+c)$, and $\tau$ can be estimated by setting

$$
z^{\prime}=z-\frac{1}{2} x, \quad y^{\prime}=y-\frac{1}{2} x .
$$

We find that $\tau^{2}=4\left|\cos z^{\prime}-\cos y^{\prime}\right|^{2}$. Now

$$
\begin{aligned}
& \exp i u[f(t-s)+f(s)-f(t-p)-f(p)] \\
& \quad=\exp i u \sum_{k=1}^{\infty} b^{k} P\left(n_{k} t, n_{k} s, n_{k} p, \omega_{k}\right) .
\end{aligned}
$$

To obtain an upper bound for the expectation of $\left\|e^{i u s}\right\|_{\infty}^{4}$ we integrate this formula, first with respect to $\omega_{1}, \omega_{2}, \cdots$ and then with respect to $s, p, t$. Note the estimation

$$
\begin{gathered}
J_{0}(R)=(2 \pi)^{-1} \int_{0}^{2 \pi} e^{i R \sin \omega} d \omega \leqq C(1+|R|)^{-1 / 2}, \quad-\infty<R<\infty . \\
(2 \pi)^{-3} \iiint \prod_{k=1}^{\infty}\left|J_{0}\left(2 u b_{k} \cdot\left|\cos n_{k} y^{\prime}-\cos n_{k} z^{\prime}\right|\right)\right| d x d y d z \\
\leqq(2 \pi)^{-2} \iint \prod_{1}^{N(u)}\left|J_{0}\left(2 u b^{k} \cdot\left|\cos n_{k} y-\cos n_{k} z\right|\right)\right| d y d z .
\end{gathered}
$$

Here $N(u)$ is the integral part of $-\frac{1}{2} \log u / \log b$. If $B_{N(u)}(y, z) \geqq r N(u)$ the product in the integral is at most $\left(C^{\prime}|u|^{-1 / 4}\right)^{r N(u)}$, a magnitude ultimately smaller than any assigned power of $|u|^{-1}$. The integral on the complement $\left\{B_{N(u)} \leqq r N(u)\right.$ is $O\left(e^{-\eta N(u)}\right)=O\left(|u|^{2-1_{\eta} / \log b}\right)$. Choosing $b$ close to 1 , we can make this $O\left(|u|^{-4 M-6}\right)$. Then by Fubini's theorem

$$
E\left(\int_{-\infty}^{\infty}|u|^{4 M+4}\left\|e^{i u \rho}\right\|_{\infty}^{4} d u\right)=\int_{-\infty}^{\infty}|u|^{4 M+4} E\left(\left\|e^{i u \rho} \mid\right\|_{\infty}^{4}\right) d u<\infty,
$$

so $\int_{-\infty}^{\infty}|u|^{4 M+4}|| e^{i u s} \|_{\infty}^{4} d u<\infty$ for almost all $\omega$ in $\Omega$. Conclusion (1) is a consequence of Holder's inequality.

It is clear that if $b^{k}$ is replaced by $k^{-2}$ for example, the condition (1) is valid for any integer $M$.

\section{REFERENCES}

1. J.-P. Kahane, Sur un théorème de Paul Malliavin, C. R. Acad. Sci. Paris 248 (1959), 2943-2944.

2. J.P. Kahane and Y. Katznelson, Contribution à deux problèmes, concernant les fonctions de la classe A, Israel J. Math. 1 (1963), 110-131.

3. J.P. Kahane and R. Salem, Ensembles parfaits et séries trigonométriques, Hermann, Paris, 1963.

4. P. Malliavin, Sur l'impossibilité de la synthèse spectrale sur la droite, C. R. Acad. Sci. Paris 248 (1959), 2155-2157.

Received October 9, 1967. 



\section{PACIFIC JOURNAL OF MATHEMATICS}

\section{EDITORS}

H. ROYDEN

Stanford University

Stanford, California

R. R Phelps

University of Washington

Seattle, Washington 98105
J. DUGUNDJI

Department of Mathematics

University of Southern California

Los Angeles, California 90007

RICHARD ARENS

University of California

Los Angeles, California 90024

\section{ASSOCIATE EDITORS}
E. F. BECKENBACH
B. H. NeumanN
F. WOLF
K. YosidA

\section{SUPPORTING INSTITUTIONS}

UNIVERSITY OF BRITISH COLUMBIA

CALIFORNIA INSTITUTE OF TECHNOLOGY

UNIVERSITY OF CALIFORNIA

MONTANA STATE UNIVERSITY

UNIVERSITY OF NEVADA

NEW MEXICO STATE UNIVERSITY

OREGON STATE UNIVERSITY

UNIVERSITY OF OREGON

OSAKA UNIVERSITY

UNIVERSITY OF SOUTHERN CALIFORNIA
STANFORD UNIVERSITY

UNIVERSITY OF TOKYO

UNIVERSITY OF UTAH

WASHINGTON STATE UNIVERSITY

UNIVERSITY OF WASHINGTON

AMERICAN MATHEMATICAL SOCIETY CHEVRON RESEARCH CORPORATION TRW SYSTEMS

NAVAL WEAPONS CENTER 


\section{Pacific Journal of Mathematics

Vol. 28, No. $1 \quad$ March, 1969

Patrick Robert Ahern, On the geometry of the unit ball in the space of real annihilating measures .............................. 1

Kirby Alan Baker, Equational classes of modular lattices ............. 9

E. F. Beckenbach and Gerald Andrew Hutchison, Meromorphic minimal surfaces ......................................... 17

Tae Ho Choe, Intrinsic topologies in a topological lattice ..............

John Bligh Conway, A theorem on sequential convergence of measures and

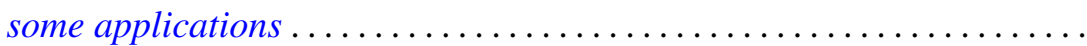

Roger Cuppens, On the decomposition of infinitely divisible probability laws without normal factor.

Lynn Harry Erbe, Nonoscillatory solutions of second order nonlinear

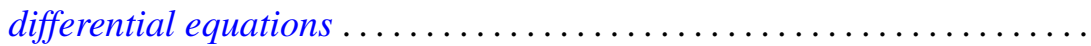

Burton I. Fein, The Schur index for projective representations of finite

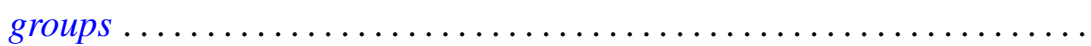

Stanley P. Gudder, A note on proposition observables............... 101

Kenneth Kapp, On Croisot's theory of decompositions ............... 105

Robert P. Kaufman, Gap series and an example to Malliavin's theorem . . . 117

E. J. McShane, Robert Breckenridge Warfield, Jr. and V. M. Warfield,

Invariant extensions of linear functionals, with applications to measures and stochastic processes ................

Marvin Victor Mielke, Rearrangement of spherical modifications ...

Akio Osada, On unicity of capacity functions ..............

Donald Steven Passman, Some 5/2 transitive permutation groups ...

Harold L. Peterson, Jr., Regular and irregular measures on groups and dyadic spaces...

Habib Salehi, On interpolation of $q$-variate stationary stochastic processes...

Michael Samuel Skaff, Vector valued Orlicz spaces generalized

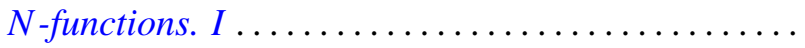

A. J. Ward, On $H$-equivalence of uniformities. II...........

Thomas Paul Whaley, Algebras satisfying the descending chain condition for subalgebras...

G. K. White, On subgroups of fixed index

Martin Michael Zuckerman, A unifying condition for implications among the axioms of choice for finite sets ................. 